Historic, Archive Document

Do not assume content reflects current scientific knowledge, policies, or practices. 

Hill's Sixty Thousand Satisfied Customers is Your Guarantee of Satisfaction

\section{Hill's Cozy Bungalow Collections SELECTION MADE EASY}

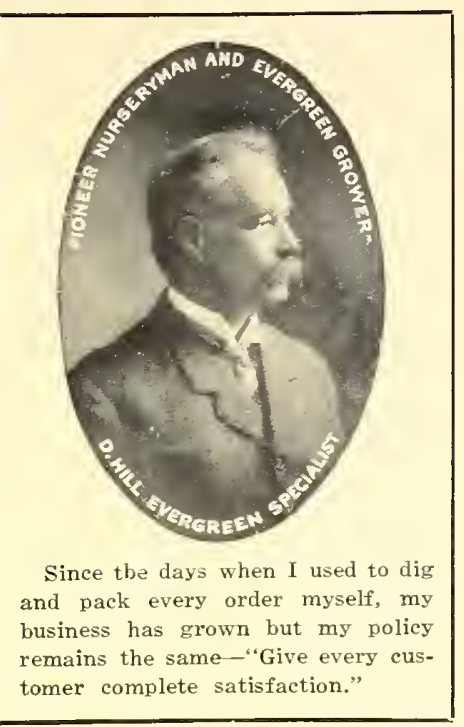

Q WVe have kept in mind the different growing habits, assuring hal'monious effects ill the

As you study these photographs of actual plantings, you ean easily picture the coziness, charm and touch of beauty that Evergreens will give your own home. Be guided by the illustrations. They faithfully portray actual plantings which you can easily reproduce.

Of course, best results depend on using Evergreens of known worth and quality-grown by Evergreen Specialist. Ever since my Evergreen business was estabished, and that's over 50 vears ago, my motto has always been, "Give every cutomer complete satisfaction." Living up to that motto all these years, together with constant, never-tiring experiment and careful growing methods, have combined to give Hill's Evergreens a national repuation for (guality, and have enabled me to build up the largest Evergreen business in America. No matter where you live in the United States, I guarantee that all trees will reach you in first class condition, or money back or shipment duplicated as you prefer. What could be fairer?

D. HILL, President.

planting and cultural directions are furnished fre? with each order.

COLLECTION “A” $\$ 100$

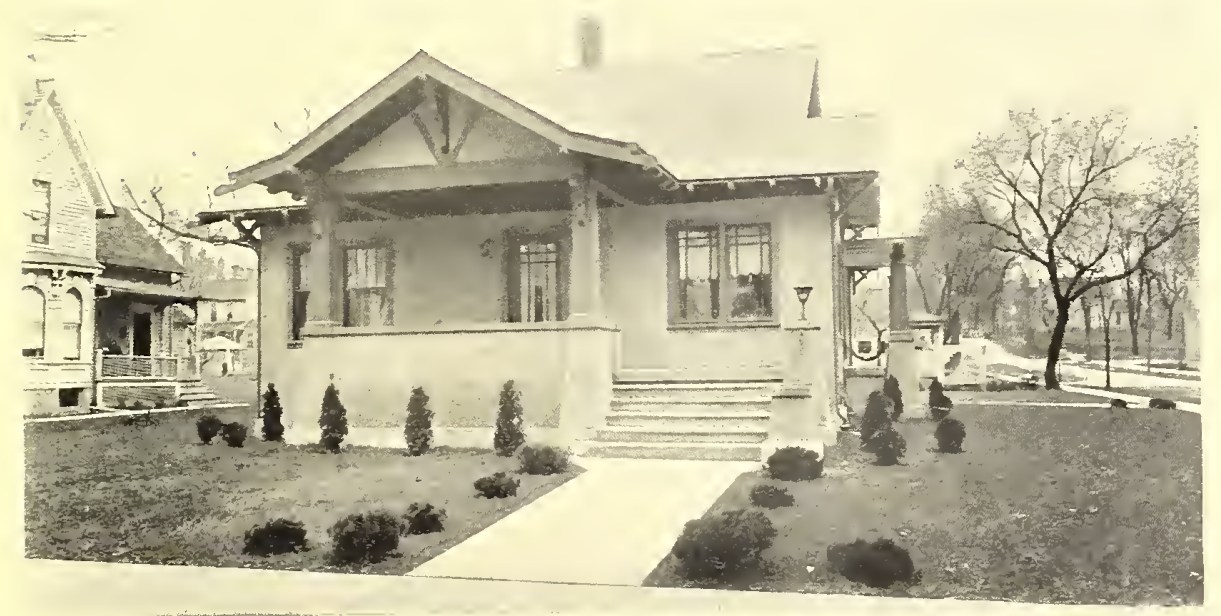

There is a cozy. simple charm about this trim little home. With the pretty little Dwarf Mlomintin Fines on each side of the walk it seems frankly open to the

The symmetrical, well formed, Pyramidal Arbor Vitaes soften the solid porch valls. Notice, too, how much wider the hou

You can easily obtain the same charming

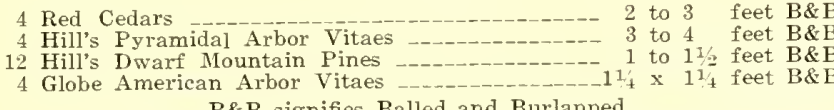

B\&B signifies Balled and Burlapped. $\$ 100.00$

COLLECTION “B” $\$ 45$

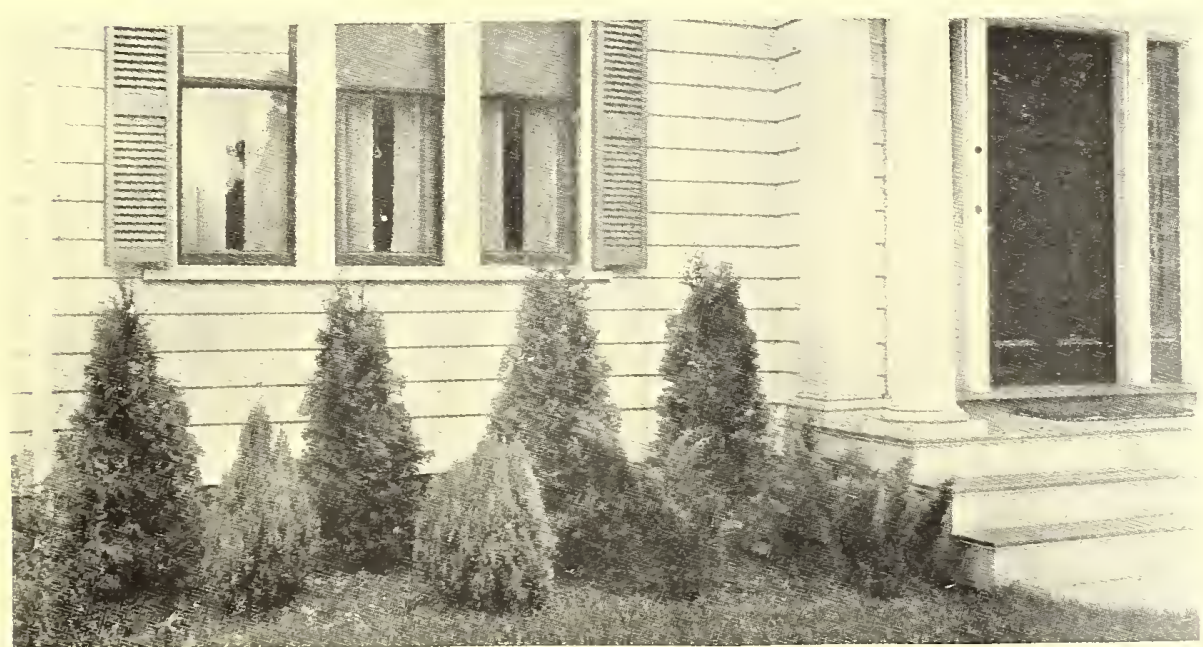

Here is an excellent example of a simple, artistic foundation planting. This sort of planting is approp

Interesting low growing Everoreens, consisting of the quaint dwarf Savin Juniper, odd little Juniper Canadensis, and the refreshing green Dwarf Mountain Pines are used in front. The handsome Pyramidal Arbor Vitaes give height the back. They also break "p the bare the house the view is equally pleasing. interest with this lovely little group.

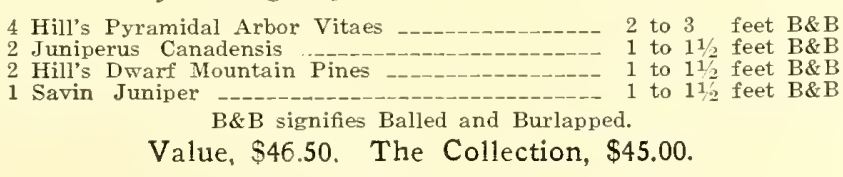

COLLECTION "C" $\$ 50$
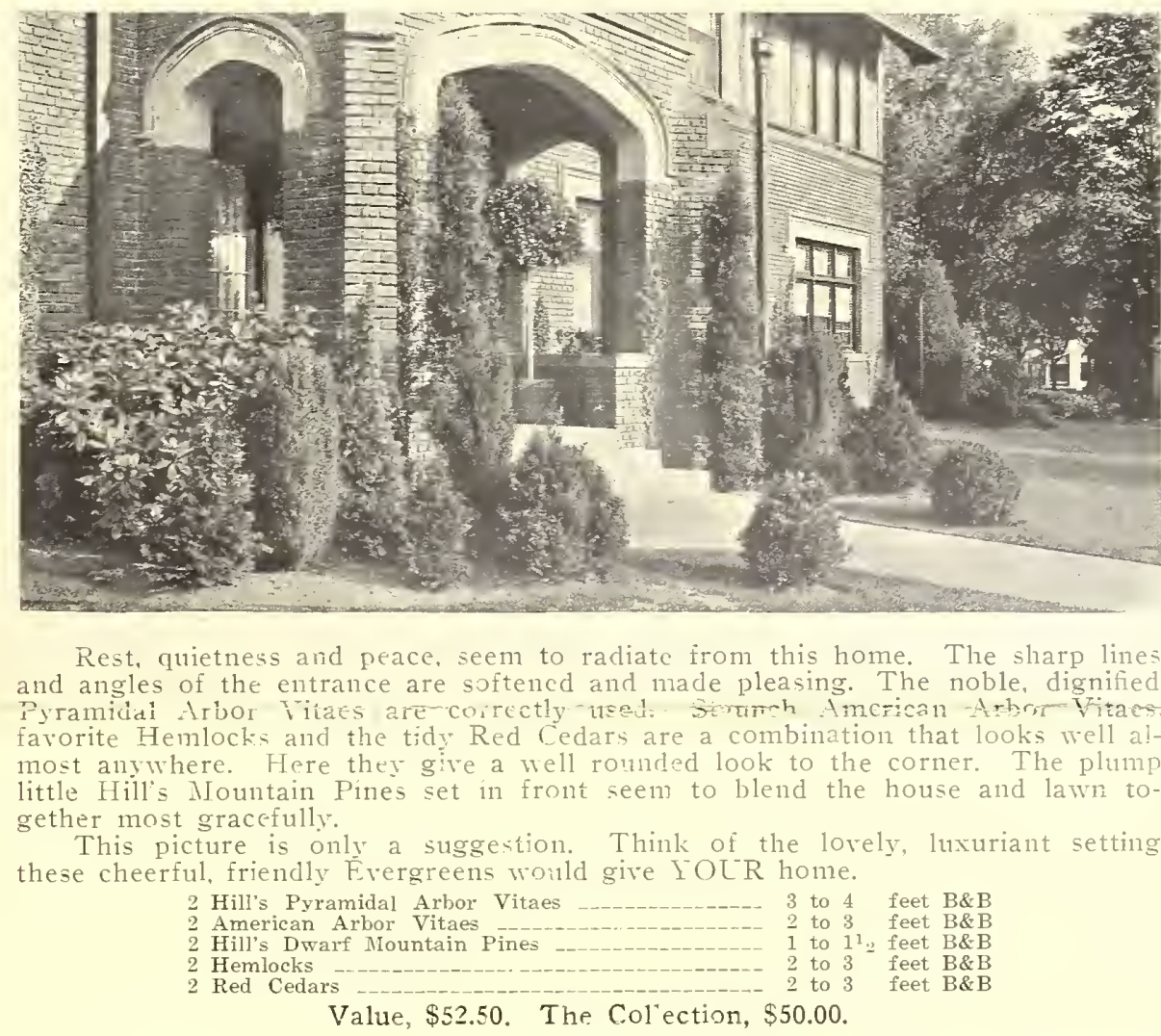

COLLECTION “D” $\$ 40$

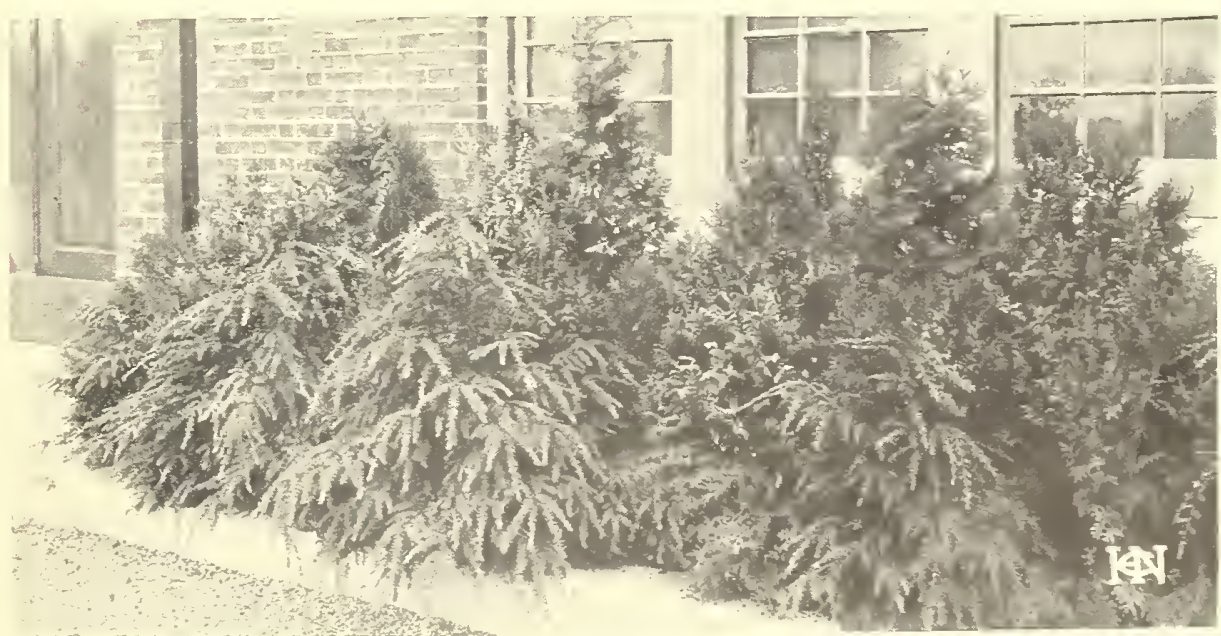

limited space. The soit,

this purpose. Thev

A few g
surroundings.

3 Hemlocks

Value, $\$ 41.00$. The Collection, $\$ 40.00$.

THE D. HILL NURSERY COMPANY, Inc. 
